\title{
EFEKTIFITAS PERMAINAN KEARIFAN BUDAYA LOKAL DIBANDINGKAN NEUROFEEDBACK TERHADAP PENURUNAN DERAJAT DEPRESI PADA PASIEN DEPRESI PASCA SKIZOFRENIA DI RUMAH SAKIT JIWA PROF. DR. SOEROJO MAGELANG
}

\author{
Sumarni DW ${ }^{1}$, Mahar Agusno ${ }^{2}$, Santi Yuliani ${ }^{3}$ \\ 1,2Bagian Ilmu Kedokteran Jiwa Fakultas Kedokteran Universitas Gadjah \\ Mada/Rumah Sakit Dr. Sardjito Yogyakarta \\ 3Dokter Pendidik Klinis Fakultas Kedokteran UGM di RSJ Prof. Dr. Soerojo \\ Magelang
}

Korespondensi: bu_sumarnidw@yahoo.com

\begin{abstract}
ABSTRAK
Latar Belakang: Skizofrenia merupakan gangguan jiwa berat, dengan kekambuhan berulang. Pasien seringkali mengalami gejala depresi. Perasaan putus asa akan kondisi penyakitnya yang tidak kunjung sembuh membuat pasien terpuruk dan kehilangan keyakinan terhadap masa depannya. Konsumsi obat terus menerus yang menimbulkan rasa bosan dan menurunkan tingkat kepatuhan sangat mengganggu proses kesembuhan pada pasien skizofrenia. Banyaknya jumlah obat yang harus mereka konsumsi, akan memperberat depresi, berisiko melakukan tindakan bunuh diri. Terapi permainan kearifan budaya lokal dan neurofeedback merupakan salah satu tatalaksana nonfarmakoterapi yang dapat digunakan terhadap depresi pada pasien pasca skizofrenia.

Tujuan: Untuk menganalisis efektifitas terapi permainan kearifan budaya lokal dibandingkan neurofeedback terhadap penurunan derajat depresi pada pasien depresi pasca skizofrenia di RSJ Prof. Dr. Soerojo Magelang.

Bahan dan Cara: Jenis penelitian eksperimental semu dengan rancangan pretest dan post test control design. Subyek penelitian adalah pasien depresi pasca skizofrenia di RSJ Prof.Dr. Soerojo Magelang

Alat penelitian yang dipergunakan adalah: (1) peralatan permainan kearifan budaya lokal; (2) alat elektromedik neurofeedback; (3) Beck Depression Inventory (BDI); (4) kuesioner sosio-demografi. Responden dibagi menjadi 4 kelompok, yaitu: kelompok yang diberi perlakuan permainan kearifan budaya lokal, kelompok yang diberi neurofeedback, kelompok yang diberi permainan kearifan budaya lokal dan neurofeedback, dan kelompok kontrol yang tidak diberi perlakuan. Efektifitas perlakuan diukur melalui pembandingan data derajat depresi sebelum perlakuan dengan data derajat depresi setelah perlakuan. Teknik analisis statistik yang dipergunakan adalah F-test dan $\chi^{2}$-test, dengan $\alpha=5 \%$.

Hasil: Terjadi penurunan skor depresi yang signifikan pada kelompok responden yang diberi perlakuan permainan kearifan budaya lokal $(-61,6 \%$; Fh $=$ $336,135 ; \mathrm{p}<0,01)$, neurofeedback $(-64,8 \% ; \mathrm{Fh}=265,283 ; \mathrm{p}<0,01)$, gabungan permainan kearifan budaya lokal dan neurofeedback $(-74,5 \%$; Fh $=397,093$; $\mathrm{p}<$ 0,01), maupun pada kelompok kontrol $(-47,4 \%$; $F h=106,333 ; p<0,01)$.

Kesimpulan: Pemberian permainan kearifan budaya lokal dan neurofeedbak merupakan metode yang efektif untuk menurunkan derajat depresi pada pasien depresi pasca skizofrenia di RSJ Prof. Dr. Soerojo Magelang.
\end{abstract}

Kata Kunci: permainan kearifan budaya lokal, neurofeedback, depresi pasca skizofrenia, derajat depresi. 


\title{
EFFECTIVENESS OF WISDOM GAME CULTURE LOCAL DECREASE COMPARED TO THE DEGREE OF DEPRESSION NEUROFEEDBACK SCHIZOPHRENIA PATIENTS DEPRESSION POST MENTAL HOSPITAL PROF. DR. SOEROJO MAGELANG
}

\author{
Sumarni DW 1 , Mahar Agusno2 ${ }^{2}$, Santi Yuliani ${ }^{3}$ \\ 1,2Psychiatric Department of Medical Faculty of Gadjah Mada University \\ Yogyakarta / Dr. Sardjito Hospital Yogyakarta \\ ${ }^{3}$ Clincal Lecture of Medical Faculty of Gadjah Mada University at Prof. Dr. \\ Soerojo Psychiatric Hospital Magelang \\ Correspondence: bu_sumarnidw@yahoo.com
}

\begin{abstract}
Background: Schizophrenia is a severe mental disorder, with repeated recurrences. Patients often experience symptoms of depression. Feelings of despair will be conditions that do not heal the disease makes the patient collapsed and lost faith in the future. Continuous consumption of drugs that cause boredom and reduce the level of compliance is very disturbing the healing process in patients with schizophrenia. A large number of drugs that should they consume, will aggravate depression, committed suicide risk. Play therapy and neurofeedback cultural wisdom is one of the management of nonfarmakoterapi that can be used against depression in patients with post schizophrenia.

Objective: To analyze the effectiveness of play therapy local wisdom than neurofeedback to decrease the degree of depression in patients with postpartum depression schizophrenia in RSJ Prof. Dr. Soerojo Magelang. Materials and Methods: This type of quasi-experimental research with pretest and post test control design. Subjects were patients with postpartum depression schizophrenia in RSJ Prof.Dr. Soerojo Magelang.

Research tools used are: (1) local cultural wisdom game equipment; (2) tool elektromedik neurofeedback; (3) Beck Depression Inventory (BDI); (4) The sociodemographic questionnaire. Respondents were divided into 4 groups: group treated the game of local wisdom, the group given neurofeedback, the group given the game of local wisdom and neurofeedback, and a control group that was not treated. Effectiveness of the treatment was measured by comparing the data the degree of depression prior to treatment with the data the degree of depression after treatment. Statistical analysis technique used is the F-test and $\chi 2$-test, with $\alpha=5 \%$.

Results: There was a significant decrease in depression scores in the group of respondents who treated the game of local wisdom (-61.6\%; Fh $=336.135 ; \mathrm{p}$ $<0.01)$, neurofeedback (-64.8\%; Fh $=265.283 ; p<0.01)$, a combination of cultural wisdom games and neurofeedback (-74.5\%; Fh $=397.093 ; p<0.01)$, as well as in the control group (-47.4\%; Fh $=106.333, p<0.01)$.

Conclusion: The provision of games of local wisdom and neurofeedbak is an effective method to reduce the degree of depression in patients with postpartum depression schizophrenia in RSJ Prof. Dr. Soerojo Magelang.
\end{abstract}

Keywords: the game of local wisdom, neurofeedback, postpartum depression schizophrenia, the degree of depression. 


\section{PENDAHULUAN}

Skizofrenia membawa beban psikologis yang berat bagi penderitanya, tidak mengherankan jika muncul reaksi kekecewaan pada penderita terhadap kondisi penyakit skizofrenia yang diderita.Perasaan rendah diri, merasa terkucilkan, dan tidak bisa berfungsi sebagaimana semestinya, membuat penderita skizofrenia putus asa dan mengalami kondisi depresi. Sedih dan putus asa, karena mengetahui sakit yang dideritanya tidak akan sembuh, perasaan tertekan harus meminum obat seumur hidup, serta kehilangan hak-haknya di mata hukum. Bila kondisi tersebut berlangsung terus dan tidak mendapatkaan penanganan yang tepat, akan berujung pada kemungkinan terjadinya bunuh diri. ${ }^{1}$

Depresi pada skizofrenia memperlihatkan adanya gambaran disforik pada setiap individu seperti sedang mengalami suatu kejadian stress, tidak bisa konsentrasi, mengisolasi diri terhadap keluarga dan lingkungan, perasaan yang kuat dalam anhedonia (apatis dan sedikitnya ketertarikan dalam segala hal) dan mood depresif, selain itu adanya keluhan dalam insomnia, sedikitnya nafsu makan atau libido, dan menurunnya fungsi psikomotor. $2,3,4$

Depresi merupakan faktor risiko yang terkait kematian karena bunuh diri pada skizofrenia, mengingat bahwa $10 \%$ dari pasien dengan skizofrenia mengakhiri hidup mereka sendiri. Pasien yang bunuh diri lebih mungkin memiliki riwayat episode depresi dan memiliki gejala depresi dipamerkan di kontak terakhir mereka. Bunuh diri di skizofrenia tampaknya berkorelasi lebih dengan keputusasaan dan aspek psikologis depresi dibandingkan dengan fitur vegetatif. Depresi juga berkaitan dengan mencoba bunuh diri. Hasil penelitian menyatakan bahwa depresi pasca skizofrenia didapatkan sebesar 62,5\% di Rumah Sakit Jiwa Prof. Dr. Soerojo Magelang. ${ }^{5}$

Mengingat besarnya pasien depresi pasca skizofrenia di Magelang menjadi jelas bahwa penanganan komprehensif terhadap pasien depresi pasca skizofrenia merupakan kebutuhan yang urgen. Pengobatan yang tepat pada kondisi depresi pasca skizofrenia bisa membantu memulihkan kembali kepercayaan diri dan mengembalikan pasien pada kondisi yang stabil dan mandiri. Pemberian tambahan obat-obatan farmakologis memang bisa membantu, tetapi tentu saja konsekuensi rasa bosan akan obat yang terus dikonsumsi dan jumlah yang semakin banyak, akan memicu rasa sedih pada pasien.

Pemberian terapi non farmakologis, seperti psikoterapi dan terapi elektromedik, bisa menjadi pilihan dalam penatalaksanaan depresi pasca skizofrenia 7 . Terapi non farmakologis lainnya yang dapat diimplementasikan untuk menurunkan derajat depresi pada pasien pasca skizofrenia adalah permainan kearifan budaya lokal dan neurofeedback. Hasil penelitian menunjukkan bahwa permainan kearifan budaya lokal dapat menuurunkan derajat depresi, gangguan kualitas tidur, dan gangguan interaksi sosial pada lansia di hunian sementara Gondang, Cangkringan $^{8}$, Sleman. Penelitian menyatakan bahwa neurofeedback dapat mengubah kondisi alfa asimetri yang abnormal pada kondisi depresi. Neurofeedback dapat efektif mengobati depresi. 9,10

Penelitian ini dilaksanakan dengan tujuan utamamengetahui efektivitas pemberian permainan kearifan budaya lokal dan neurofeedback terhadap penurunan derajat depresi pada pasien depresi pasca skizofrenia di Rumah Sakit Jiwa Prof. Dr. Soerojo, Magelang, dan 
secara khusus penelitian ini bertujuan untuk: (a) Menganalisis pengaruh permainan kearifan budaya lokal terhadap penurunan derajat depresi pada pasien depresi pasca skizofrenia; (b) Menganalisis pengaruh neurofeedback terhadap penurunan derajat depresi pada pasien depresi pasca skizofrenia; (c) Menganalisis pengaruh permainan kearifan budaya lokal dan neurofeedback terhadap penurunan derajat depresi pada pasien depresi pasca skizofrenia; melalui analisis perbandingan derajat depresi antara sebelum pemberian perlakuan dengan derajat depresi setelah pemberian perlakuan pada pasien depresi pasca skizofrenia di Rumah Sakit Jiwa Prof. Dr. Soerojo, Magelang.

\section{BAHAN DAN CARA PENELITIAN}

Penelitian ini akan
dilaksanakan dalam jenis penelitian
eksperimental semu dengan
menggunakan rancangan pre-test and
post-test control design. Untuk
mempertajam hasil kuantitatif
dilakukan pendekatan kualitatif.

Responden dibagi menjadi 4 kelompok responden (KR), yakni: (a) Kelompok responden yang diberi perlakuan berupa permainan berbasis budaya lokal yang dikemas dalam bentuk tarian (PT), untuk selanjutnya disebut sebagai kelompok responden PT (disingkat KR-PT); (b) Kelompok responden yang diberi perlakuan berupa neurofeedback (NF), untuk selanjutnya disebut sebagai kelompok responden NF (disingkat KR-NF); (c) Kelompok responden yang diberi perlakuan berupa permainan berbasis budaya lokal yang dikemas dalambentuk tarian (PT) dan neurofeedback (NF), untuk selanjutnya disebut sebagai kelompok responden $\mathrm{PT}+\mathrm{NF}$ (disingkat $\mathrm{KR}$ $\mathrm{PT}+\mathrm{NF}$ ); (d) Kelompok responden yang tidak diberi perlakuan PT maupun NF, untuk selanjutnya disebut sebagai kelompok responden kontrol (disingkat KR-K).

Populasi penelitian adalah seluruh pasien depresi pasca skizofrenia yang ada di Rumah Sakit Jiwa Prof. Dr. Soerojo Magelang. Sedangkan, subjek penelitian adalah pasien depresi pasca skizofrenia yang ada di Rumah Sakit Jiwa Prof. Dr. Soerojo Magelang yang memenuhi kriteria inklusi dan eksklusi sebagai berikut: (a) Kriteria inklusi adalah: pasien depresi pasca skizofrenia; (b) Kriteria eksklusi adalah (Pasien dengan komorbiditas fisik (hipertensi, diabetes, anemia, infeksi, gangguan jantung, epilepsi, parkinson, post stroke); Pasien yang mengkonsumsi mood stabilizer; Pasien yang mengkonsumsi anti depresan; Pasien yang sedang dalam kontrak psikoterapi; Pasien yang mendapatkan terapi ECT)

Dalam penelitian ini, digunakan alat-alat penelitian meliputi: (a) Alat neurofeedback; (b) Instrumen depresi (Beck Depression Inventory); (c) Modul permainan kearifan budaya local; (d) Kostum, peralatan permainan, dan peralatan audio untuk memperdengarkan atau memainkan bunyi gamelan atau musik tradisional; (e) Pedoman wawancara mendalam.

Pelaksanaan penelitian dilakukan di Rumah Sakit Jiwa Prof. Dr. Soerojo Magelang pada bulan Juni-Oktober 2015. Data primer diperoleh melalui wawancara, pemeriksaan depresi, dan observasi langsung di tempat penelitian. Sedangkan data sekunder diperoleh melalui cuplikan data yang dimiliki oleh rekam medis Rumah Sakit Jiwa Prof. Dr. Soerojo Magelang, maupun sumber pustaka lainnya.

Wawancara dilakukan dengan metode wawancara terstruktur dan wawancara mendalam (indepth interview), terutama untuk melakukan pendalaman dan pengujian integritas atau kesakihan 
data dari responden. Pengumpulan data dilakukan 2 kali, yaitu sebelum diberikan perlakuan/perlakuan bagi KR-PT, KR-NF, dan KR-PT+NF (data awal) dan sesudah diberikannya perlakuan/perlakuan bagi KR-PT, KR$\mathrm{NF}$, dan KR-PT+NF (data akhir).

Wawancara dan pengukuran derajat depresi dilakukan oleh Dr. Dra. Sumarni DW., M.Kes dan dr. Mahar Agusno, Sp.KJ(K) beserta 3 orang dokter spesialis kedokteran jiwa dari Rumah Sakit Jiwa Prof. Dr. Soerojo Magelang, dan dibantu oleh 6 orang perawat. Neurofeedback dilakukan oleh dr. Santi Yuliani, M.Sc., Sp.KJ., seorang dokter spesialis jiwa dari Rumah Sakit Jiwa Prof. Dr. Soerojo Magelang, dibantu oleh 2 orang perawat elektromedik. Pemberian permainan kearifan budaya lokal dilakukan oleh Dr. Dra. Sumarni DW., M.Kes dibantu oleh 3 dokter spesialis jiwa dari Rumah Sakit Jiwa Prof. Dr. Soerojo Magelang, dan dibantu oleh 6 orang perawat bagian rehabilitasi medik.

Pemberian perlakuan berupa permainan kearifan budaya lokal yang dikemas dalam bentuk tarian bagi KRPT, sebanyak 2 kali dalam 2 minggu. Pemberian perlakuan berupa neurofeedback bagi KR-NF sebanyak 2 kali dalam 2 minggu. Pemberian perlakuan berupa permainan kearifan budaya lokal yang dikemas dalam bentuk tarian sebanyak 2 kali dalam 2 minggu dan neurofeedback sebanyak 2 kali dalam 2 minggu, pada $\mathrm{KR}-\mathrm{PT}+\mathrm{NF}$.

Uji kemaknaan terhadap perbedaan variasi nilai antar variabel atau perbedaan lebih dari dua nilai rata-rata, dilakukan menggunakan metode anova atau F-test, dengan menggunakan tingkat kemaknaan $(\alpha)=5 \%$.

\section{HASIL}

Responden penelitian ini adalah 100 orang pasien depresi pasca skizofrenia dari bangsal Dworowati dan bangsal Kresno Rumah Sakit Jiwa (RSJ) Prof. Dr. Soerojo Magelang. Responden dibagi menjadi 4 kelompok sama besar, masing-masing terdiri dari 25 orang responden. Semua respoden memperoleh pengananan farmakoterapi sesuai prosedur dari RSJ Prof. Dr. Soerojo, namun setiap kelompok responden memperoleh perlakuan non farmakoterapi yang berbeda-beda.

Kelompok responden pertama diberi perlakuan berupa permainan kearifan budaya lokal yang dikemas dalam tarian, selanjutnya disebut Kelompok Responden PT (disingkat KR-PT). Kelompok responden kedua diberi perlakuan berupa neurofeedback, selanjutnya disebut Kelompok Responden NF (disingkat KR-NF). Kelompok responden ketiga diberi perlakuan berupa gabungan antara permainan kearifan budaya lokal dan pelatihan neurofeedbcak, selanjutnya disebut Kelompok Responden $\mathrm{PT}+\mathrm{NF}$ (disingkat KR$\mathrm{PT}+\mathrm{NF})$. Kelompok responden keempat sebagai kelompok kontrol tidak diberi perlakuan permainan kearifan budaya lokal maupun pelatihan neurofeedbcak, selanjutnya disebut Kelompok Responden K (disingkat KR-K). 
1. Karakteristik Responden

Tabel 1. Karakteristik Responden

\begin{tabular}{ccccccccc}
\hline & $\mathbf{F}$ & $\%$ & $\mathbf{F}$ & $\%$ & $\mathbf{F}$ & $\%$ & $\mathbf{F}$ & $\%$ \\
\hline Usia & & & & & & & & \\
$20-29$ & 9 & 36 & 6 & 24 & 7 & 28 & 10 & 40 \\
$30-39$ & 12 & 48 & 16 & 64 & 13 & 52 & 14 & 56 \\
$\geq 40$ & 4 & 16 & 3 & 12 & 5 & 20 & 1 & 4 \\
\hline Jenis Kelamin & & & & & & & & \\
Laki-Laki & 16 & 64 & 16 & 64 & 13 & 52 & 15 & 60 \\
Perempuan & 9 & 36 & 9 & 36 & 12 & 48 & 10 & 40 \\
\hline Status kawin & & & & & & & & \\
Belum Kawin & 5 & 20 & 2 & 8 & 1 & 4 & 5 & 20 \\
Kawin & 19 & 76 & 20 & 80 & 21 & 84 & 16 & 64 \\
Janda/Duda & 1 & 4 & 3 & 12 & 3 & 12 & 4 & 16 \\
\hline
\end{tabular}

Sumber: Data primer, 2015

Sebagian besar responden pada semua kelompok, berusia 30-39 tahun dengan rata-rata proporsi $55 \%$. Rasio antara banyaknya responden laki-laki dibanding responden perempuan, berkisar $3: 2$. Rata-rata poporsi responden berstatus kawin sebesar $76 \%$, sementara rata-rata proporsi responden berstatus janda atau duda sebesar $11 \%$.

\section{Skor Depresi Sebelum Pemberian Perlakuan}

Dalam penelitian eksperimen semu dengan pemberian perlakuan/perlakuan kepada lebih dari 1 kelompok responden, harus dipenuhi syarat homogenitas responden yaitu bahwa kondisi awal variabel yang akan diukur dan dianalisis, harus tidak berbeda secara signifikan antar kelompok responden. Dalam penelitian ini, variabel yang akan diukur dan dianalisis adalah derajat depresi responden dengan proxy skor depresi yang diukur dengan instrumen Beck Depression Inventory.

Tabel 2. Rata-rata Skor Depresi Semua Kelompok Responden Sebelum Pemberian Perlakuan Kepada KR-PT, KR-NF, dan KR-PT+NF

\begin{tabular}{ccccccc}
\hline Variabel & KR-PT & KR-NF & $\begin{array}{c}\text { KR- } \\
\mathbf{P T}+\mathbf{N F}\end{array}$ & KR-K & \multicolumn{2}{c}{ Analisis Statistik } \\
\cline { 6 - 7 } & & & 34,16 & 34,28 & 0,1340 & 0,9395
\end{tabular}

Skor Depresi

Sumber: Data primer, 2015

Hasil analisis statistik dengan teknik anova menunjukkan tidak ada perbedaan yang signifikan pada ratarata skor depresi antar kelompok responden $\left(F_{h}=0,1340 ; p=0,9395>\right.$ $0,05)$. Dengan demikian, persyaratan homogenitas responden dalam penelitian ini telah terpenuhi.
3. Perubahan Skor Depresi antara Sebelum Pemberian Perlakuan (Skor Awal) dan Sesudah Pemberian Perlakuan (Skor Akhir) pada Kelompok Responden yang Diberi Permainan dalam Tarian (KR-PT) Setelah pemberian perlakuan berupa permainan kearifan budaya 
lokal yang dikemas dalam bentuk tarian pada kelompok responden PT (KR-PT), terjadi penurunan skor depresi yang signifikan $\left(\mathrm{F}_{\mathrm{h}}=336,135\right.$; $\mathrm{p}=2,564 \mathrm{E}-23<0,05)$. Rata-rata skor depresi pada KR-PT berkurang dari
34,32 sebelum pemberian perlakuan, menjadi 13,08 setelah pemberian perlakuan, atau mengalami penurunan sebesar $61,6 \%$.

Tabel 3. Perubahan Rata-rata Skor Depresi pada Kelompok Responden PT Antara Sebelum dengan Sesudah Pemberian Perlakuan

\begin{tabular}{llllcc}
\hline \multirow{2}{*}{ Variabel } & $\begin{array}{c}\text { Sebelum } \\
\text { Perlakuan }\end{array}$ & $\begin{array}{c}\text { Sesudah } \\
\text { Perlakuan }\end{array}$ & Perubahan & \multicolumn{2}{c}{ Analisis Statistik } \\
\cline { 5 - 6 } & & & & $\mathbf{F}_{\mathbf{h}}$ & $\mathbf{p}$ \\
Rata-rata & 34,32 & 13,08 & $-61,6 \%$ & 336,135 & $2,564 \mathrm{E}-23$ \\
Skor Depresi & & & & &
\end{tabular}

Sumber: Data primer, 2015

4. Perubahan Skor Depresi antara Sebelum Pemberian Perlakuan (Skor Awal) dan Sesudah Pemberian Perlakuan (Skor Akhir) pada Kelompok Responden yang Diberi Pelatihan Neurofeedback (KR-NF)

Tabel 4. Perubahan Rata-rata Skor Depresi pada Kelompok Responden NF Antara Sebelum dengan Sesudah Pemberian Perlakuan

\begin{tabular}{lccccc}
\hline \multicolumn{1}{c}{ Variabel } & $\begin{array}{c}\text { Sebelum } \\
\text { Perlakuan }\end{array}$ & $\begin{array}{c}\text { Sesudah } \\
\text { Perlakuan }\end{array}$ & \multirow{2}{*}{ Perubahan } & \multicolumn{2}{c}{ Analisis Statistik } \\
\cline { 5 - 6 } $\begin{array}{l}\text { Rata-rata } \\
\text { Skor Depresi }\end{array}$ & 34,72 & 12,20 & $-64,8 \%$ & 265,283 & $3,475 \mathrm{E}-21$ \\
\hline
\end{tabular}

Sumber: Data primer, 2015 $\begin{array}{lcr}\text { Pemberian } & \text { perlakuan } & \text { berupa } \\ \text { pelatihan } & \text { neurofeedback } & \text { pada }\end{array}$ kelompok responden NF (KR-NF), telah menurunkan rata-rata skor depresi secara signifikan $\left(\mathrm{F}_{\mathrm{h}}=\right.$ 265,283; $p=3,475 E-21<0,05)$. Ratarata skor depresi pada KR-NF berkurang sebesar $64,8 \%$ yaitu dari 34,72 sebelum pemberian perlakuan, menjadi 12,20 setelah pemberian perlakuan.

5. Perubahan Skor Depresi antara Sebelum Pemberian Perlakuan (Skor Awal) dan Sesudah Pemberian Perlakuan (Skor Akhir) pada Kelompok

\section{Responden yang Diberi Permainan dalam Tarian dan Pelatihan Neurofeedback (KR- PT+NF)}

Rata-rata skor depresi pada kelompok responden $\mathrm{PT}+\mathrm{NF}$ (KR$\mathrm{PT}+\mathrm{NF})$ mengalami penurunan yang signifikan $\left(\mathrm{F}_{\mathrm{h}}=397,093 ; \mathrm{p}=7,409 \mathrm{E}-\right.$ $25<0,05)$ setelah diberi perlakuan permainan kearifan budaya lokal yang dikemas dalam tarian dan pelatihan neurofeedback. Rata-rata skor depresi pada KR-PT+NF berkurang dari 35,16 sebelum pemberian perlakuan, menjadi 8,84 setelah pemberian perlakuan atau mengalami penurunan sebesar $74,5 \%$. 
Tabel 5. Perubahan Rata-rata Skor Depresi pada Kelompok Responden NF Antara Sebelum dengan Sesudah Pemberian Perlakuan

\begin{tabular}{|c|c|c|c|c|c|}
\hline \multirow[b]{2}{*}{ Variabel } & \multirow{2}{*}{$\begin{array}{l}\text { Sebelum } \\
\text { Perlakuan }\end{array}$} & \multirow{2}{*}{$\begin{array}{l}\text { Sesudah } \\
\text { Perlakuan }\end{array}$} & \multirow{2}{*}{ Perubahan } & \multicolumn{2}{|c|}{ Aanalisis Statistik } \\
\hline & & & & $\mathbf{F}_{\mathrm{h}}$ & $\mathbf{p}$ \\
\hline $\begin{array}{l}\text { Rata-rata } \\
\text { Skor Depresi }\end{array}$ & 34,72 & 12,20 & $-64,8 \%$ & 265,283 & $3,475 \mathrm{E}-21$ \\
\hline
\end{tabular}

Sumber: Data primer, 2015

6. Perubahan Skor Depresi dari Skor Awal ke Skor Akhir Kelompok Responden Kontrol (KR-K)

Tabel 6. Perubahan Rata-rata Skor Depresi pada Kelompok Responden NF Antara Skor Awal dengan Skor Akhir

\begin{tabular}{|c|c|c|c|c|c|}
\hline \multirow[b]{2}{*}{ Variabel } & \multirow{2}{*}{ Skor Awal } & \multirow{2}{*}{$\begin{array}{c}\text { Skor } \\
\text { Akhir }\end{array}$} & \multirow{2}{*}{ Perubahan } & \multicolumn{2}{|c|}{ Analisis Statistik } \\
\hline & & & & $F_{h}$ & $\mathbf{p}$ \\
\hline $\begin{array}{l}\text { Rata-rata } \\
\text { Skor } \\
\text { Depresi }\end{array}$ & 34,28 & 18,20 & $-47,4 \%$ & 106,330 & $\begin{array}{c}9,1835 \mathrm{E}- \\
14\end{array}$ \\
\hline
\end{tabular}

Rata-rata skor depresi pada kelompok responden kontrol (KR-K) yang menerima penanganan farmakoterapi dan tidak memperoleh perlakuan berupa permaian kearifan budaya lokal yang dikemas dalam tarian maupun pelatihan neurofeedback, juga mengalami penurunan yang signifikan $\left(F_{h}=106,330 ; p=9,185 E-\right.$ $14<0,05)$, meskipun penurunannya tidak sebesar penurunan pada KR-PT, KR-NF, dan KR-PT+NF. Rata-rata skor depresi pada KR-K berkurang sebesar $47,4 \%$ yakni dari skor awal sebesar 34,28 menjadi skor akhir sebesar 18,82 .

7. Perbandingan Penurunan Skor Depresi dari Sebelum Pemberian Perlakuan (Skor Awal) ke Sesudah Pemberian Perlakuan (Skor Akhir) Antar Kelompok Responden

Tabel 7. Perbedaan Rata-Rata Skor Depresi antara Sebelum Perlakuan dan Sesudah Perlakuan Berdasarkan Kelompok Permianan, Kelompok Neurofeedback, Kelompok Gabungan Permainan Kearifan Budaya Lokal dan Neurofeedback.

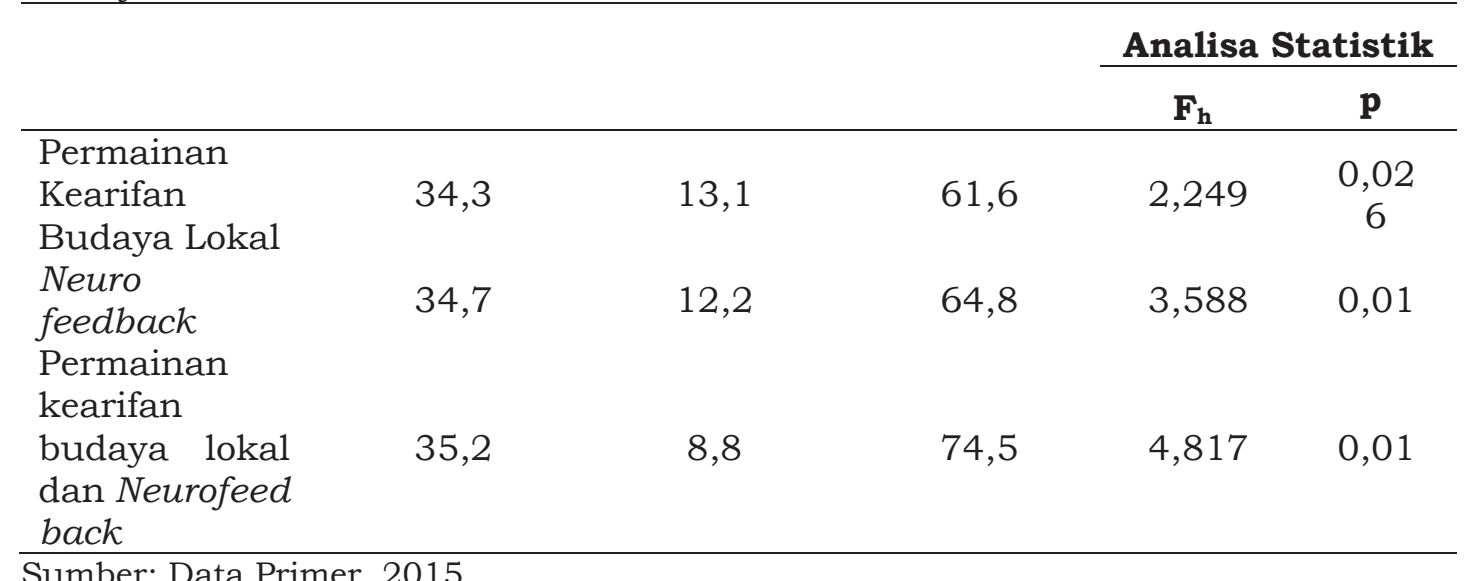


Ada perbedaan rata-rata skor depresi yang signifikan antara sebelum dan sesudah perlakuan pada semua kelompok pada kelompokkelompok permainan kearifan budaya lokal ada perbedaan yang signifikan dengan $F=2,249 \quad \mathrm{p}<0,026$; pada kelompok neurofeedback signifikan $\mathrm{F}=3,588$ dengan $\mathrm{p}<0,01$; kelompok gabungan neurofeedback ada perbedaan yang dan permainan kearifan budaya lokal ada perbedaan yang signifikan $p<0,084 \quad(p<0,10)$ dengan $F=4,87 \mathrm{p}<0,01$. Berdasarkan perbedaan perlakuan yang paling efektif dapat menurunkan skor depresi urutan pertama adalah perlakuan gabungan permainan kearifan budaya lokal dan neurofeedback, kedua adalah neurofeedback, ketiga adalah permainan kearifan budaya lokal.

\section{Perubahan Skor Depresi antara Sebelum dan Sesudah Perlakuan pada Masing-Masing Kelompok}

Tabel 8. Perubahan Rata-Rata Skor Depresi antara Sebelum dan Sesudah Perlakuan pada Masing-Masing Kelompok

\begin{tabular}{|c|c|c|c|}
\hline \multirow{2}{*}{ Perlakuan } & \multirow{2}{*}{ Perubahan } & \multicolumn{2}{|c|}{ Analisa Statistik } \\
\hline & & $\mathbf{F}_{\mathbf{h}}$ & $\mathbf{p}$ \\
\hline $\begin{array}{lll}\text { Permainan } & \text { Kearifan } & \text { Budaya } \\
\text { Lokal }\end{array}$ & $-61,6$ & & \\
\hline Neurofeedback & $-64,8$ & 36,578 & $6,604 \mathrm{E}-16$ \\
\hline $\begin{array}{l}\text { Permainan Kearifan Budaya } \\
\text { Lokal dan Neurofeedback }\end{array}$ & $-74,5$ & & \\
\hline Kontrol & $-47,4$ & & \\
\hline
\end{tabular}

Sumber: Data Primer, 2015

Hasil analisa statsitik menunjukkan ada perubahan yang signifikan $\left(\mathrm{F}_{\mathrm{h}}=36,578 ; \mathrm{p}=6,604 \mathrm{E}-16\right.$ $<0,001)$; antara masing-masing kelompok perlakuan terhadap penurunan skor depresi.

\section{PEMBAHASAN}

Pemberian permainan kearifan budaya lokal yang dikemas dalam tarian berpengaruh efektif terhadap penurunan derajat depresi pada pasien depresi pasca Skizoferenia di RSJ Prof. Dr. Soerojo Magelang. Hasil ini dikarenakan permainan kearifan budaya lokal yang dikemas dalam tarian diiringi degan lagu-lagu dan musik yang berulang-ulang akan memberikan rasa senang, meningkatkan semangat, meningkatkan kerjasama, dan meningkatkan interaksi social, meningkatkan konsentrasi. Hasil penelitian ini sesuai dengaan penelitian Sumarni yang menyatakan bahwa kegiatan menari dalam permainan kearifan budaya lokal dapat meningkatkan interaksi sosial, fungsi kognitif dan dapat menurunkan depresi pada lansia.

Dalam permainan dan tarian kearifan budaya lokal dapat meningkatkan aktivitas fisik. Aktifitas fisik dapat meningkatkan suhu tubuh, meningkatkan relaksasi, meningkatkan aliran darah ke otak dan efisiensi dari neurotransmiter, kemampuan interaksi sosial dan harga diri ${ }^{11}$. Aktifitas fisik dapat meningkatkan endorphine ${ }^{12}$, Norephineprine dan growth hormone/GH. ${ }^{13}$ Peningkatan aktivitas fisik darlam permainan dan tarian kearifan budaya lokal dapat menurunkan derajat depresi.

Peneliti Dezeache menyebutkan tertawa bersama-sama dalam menari, bermain dapat meningkatkan endorphine surge (lonjakan endorphin) yang dapat ditularkan pada teman- 
teman yang lain. Permainan dapat memberikan rasa gembira, mengurangi kejenuhan dan kelelahan, meningkatkan kemampuan bekerjasama dan berbagi tugas, meningkatkan kebugaran dan mengurangi beban psikologis, serta memperbaiki kondisi mental dan menurunkan derajat depresi.

Kegembiraan disertai tertawa lepas dapat mempengaruhi kadar neurotransmiter dan hormon-hormon di otak. Neurotransmiter tersebut dopamine dan serotonine, serta hormon oksitosin dan endorfin. Dopamin berhubungan dengan kadar kepuasan dan kadarnya akan meningkat bila seseorang sebagi individu merasa penting atau dibutuhkan orang lain. Oksitosin kadarnya meningkat bila seseorang saling mempercayai satu sama lain. Endorfin kadarnya meningkat bila seseorang merasa bahagia dan rileks. ${ }^{15}$

Dalam kegiatan menari dan bermain bisa tertawa bersama-sama. Kegiatan permainan dalam secara berkelompok mendapatkan kepuasan karena dapat melakukan permaianan kearifan budaya lokal bersama-sama. Harga diri individu meningkat karena sebagian besar permainankearifan budaya lokalmasih saling membutuhkan kerjasama yang baik antar individu. Dengan demikian individu akan merasa bahwa dirinya penting dan dibutuhkan oleh temantemannya. Adanya kerjasama ini juga menciptakan suasana yang santai dan rileks sehingga hal ini juga akan berpengaruh pada kondisi kejiwaan individu.

Musik yang berulang-ulang dan juga keras akan mengurangi halusinasi yang sering dialami oleh penderita Skozofrenia sehingga akan mengurangi depresi pasca Skizofrenia mempercepat penyembuhan.

Penurunan derajat depresi pada kelompok perlakuan neurofeedback, dengan pelatihan ini pasien mampu mengontrol dan mengelola sendiri terjadinya reaksi fisiologi otaknya. Pada pelatihan ini, pasien mendapatkan umpan balik (feedback) secara langsung dari alat pelatihan apabila pasien mampu mengendalikan dan mengarahkan gelombang otaknya yang sesuai dengan arahan pelatihan. Alat neurofeedback akan menterjemahkan gelombang otak pasien dalam bentuk digital dan ada proses scoring yang dimunculkan di akhir sesi, sehingga pasein bisa mendapatkan direct feedback apabila pasien benar dalam proses mengendalikan gelombang otaknya. Penelitian neurophsyological oleh Davidson menunjukkan bahwa sejumlah pasien depresi memiliki kelebihan alfa pada bagian otak kiri depan dengan pola pelatihan ini, kondisi alfa menjadi normal dan depresi menjadi teratasi.

Dengan neurofeedback, regulasi peningkatan semangat, motivasidan konsentrasi dapat diperbaiki, juga rentang tidur pada kondisi depresi juga bisa dinormalkan kembali. Hasil penelitian menemukan bahwa neurofeedback dapat mengubah kondisi alfa asimetri yang abnormal pada kondisi depresi. 9 Neurofeedback efektif dalam mengobati kondisi depresi.17,10 Selain itu neurofeedback telah terbukti memberikan efek yang permanen pada pengobatan depresi. ${ }^{18}$

Gabungan perlakuan permainan, tarian kearifan budaya lokal dengan neurofeedback akan mempercepat penurunan derajat depresi karena secara sosial budaya dalam permainan kearifan budaya lokal yang dikemas dalam tarian dapat meningkatkan kesehatan fisik, interaksi sosial, percaya diri, harga diri, meningkatkan endorpine, norepineprine, growth hormone, dopamine, dan serotonin dapat menurunkan depresi.

Pelatihan Neurofeedback akan memperbaiki kondisi alfa di bagian otak kiri depan yang tidak normal 
menjadi normal, akan meningkatkan semangat, motivasi, konsentrasi dan kualitas tidur sehingga akan mempercepat penurunan skor depresi pada pasien depresi pasca Skizofrenia.

\section{KESIMPULAN}

1. Permainan kearifan budaya lokal berpengaruh efektif terhadap penurunan derajat depresi pada pasien depresi pasca Skizofrenia di RSJ Prof. Dr. Soerojo Magelang.

2. Neurofeedback berpengaruh efektif terhadap penurunan derajat depresi padda pasien depresi pasca Skizofrenia di RSJ Prof. Dr. Soerojo Magelang

3. Permainan kearifan buadya lokal bersama neurofeedback berpengaruh paling efektif terhadap penurunan derajat depresi pada pasien pasca Skizofrenia di RSJ Prof. Dr. Soerojo Magelang.

\section{SARAN}

1. Bagian rehabilitasi untuk mengimplementasikan permainan kearifan budaya lokal dalam kegiatan menari pada pasien pasca Skizofrenia di RSJ Prof. Dr. Soerojo Magelang.

2. Bagian medik untuk memberikan terapi yang holistik dengan melakukan kombinasi farmakoterapi, neurofeedback dantarian permainan kearifan budaya lokal dalam penanganan pasien depresipasca skizofreniadi RSJ Prof. Dr. Soerojo Magelang.

\section{DAFTAR PUSTAKA}

1. Cheminsky E, Bowie C, Anderson HP., Depression in Schizophrenia: Methodolical Artifact or Distint Feature of the Illness,. J.Neuro.Psyscy. 2008. 20:4.

2. Birchwood M, Iqbal $Z$, Upthegrove R., Psychological pathways to depression in schizophrenia: studies in acute psychosis, post psychotic depression and auditory hallucination.

Eur.Arch.PsychiatryClinNeurosci. 2005. 55: 202-212.

3. Upthegrove R. Depression in Schizophrenia and Early Psychosis: Implications for assessment and treatment, $a d v$. Psyc.treat, vol 15. 2009. p 372379.

2. Pelliza L, Ferrari A., Anhedonia in Schizophrenia and Major Depression, State or Trait?, Annels of General Psyciatry. 2009. 8:22.

3. Amir. Depresi Aspek Neurobiologi Diagnosis Dengan Tata Laksana. Jakarta: Balai Penerbit Fakultas Kedokteran Universitas Indonesia. 2005

4. Suharto, Hesti Kuncoro. Hubungan Dukungan Sosial dengan Depresi pada Pasien Skizofrenia yang Mengalami Kekambuhan Rawat Inap di RSJ Prof Dr Soerojo Magelang. Tesis. Bagian Ilmu Kedokteran Jiwa Fakultas Kedokteran Universitas Gadjah Mada/ RSUP Dr. Sardjito. Yogyakarta. 2013.

5. Johnson, D. A. W. Studies of depressive symptoms in schizophrenia: I. The prevalence of depression and its possible causes; II. A two-year longitudinal study of symptoms; III. A double-blind trial of orphenadrine against placebo; IV. A double-blind trial of nortriptyline for depression in chronic schizophrenia. British Journal of Psychiatry, 1981. 139, 89-101.

2. Pengaruh Permainan Humor Kearifan Budaya Lokal dan Dukungan Spiritual terhadap Depresi. Gangguan Interaksi Sosial, Gangguan Kognitif dan Kualitas Tidur Lansia di Huntap Gondang Kabupaten Sleman. Laporan Penelitian Dana Masyarakat FK UGM. 2012. 
3. Baehr, E, Miller, E, Rosenfeld, JP \& Baehr, R. Changes in frontal brain asymmetry associated with premenstrual dysphoric disorder: A single case study. Journal of Neurotherapy, 8(1). 2004 29-42.

4. Walker, JE, Lawson, R \& Kozlowski, G. Current Status of QEEG and Neurofeedback in The Treatment of Depression. Chapter in J.R. 2007.

5. Foc, K.R. The Influence of Phsycal Activity on Mental Wellbeing. Public Health Nutrition. 2007. Vol. 2: 411-418.

6. Leuenburger. A Endorphrine, Exercise and Addictions: A Review of Exercise Dependence, Impuls. The Premiere Journal for Undergraduate Publications in The Neuroscience. 2006

7. Poweds, S.K. Hormon Responses to Exercise (Internet). Diakses dari http:

//www.depts.ttu.edu/hess/meco $\mathrm{mb} /$ documents/ess3305/ppt/ch ap05.pdf//. 2009
8. Dezeache. G., Dunbar. Sharing the Joke: The Size of Natural Laughter Groups. Journal Evolution and Human Behavior. United Kingdom. 2012.

9. Stahl, S.M. Stahl's Essential Psychopharmacology:

Neuroscientific Basis and Practical Applications, $3^{\text {rd }}$ edition. New York: Cambridge University Press. 2008. pp. 365-458.

10. Davidson, R.J., Affective style and affective disorders: Perspectives from affective neuroscience. Cognition \& Emotion, 12, 307-330. 1998.

11. Hammond, D. Neurofeedback with anxiety and affective disorders. Child \& Adolescent Psychiatric Clinics of North America. 2005. 4(1), 105-123.

12. Baehr, E, Rosenfeld, JP \& Baehr, R. Clinical use of an alpha asymmetry neurofeedback protocol in the treatment of mood disorders: Follow-up study 1 to 5 years post therapy. Journal of Neurotherapy. 2001.4(4), 11-18. 